\title{
One Planet Living and the legitimacy of sustainability governance: From standardised information to regenerative systems
}

Jan Gerhards, Dan Greenwood

\begin{abstract}
The last two decades have seen the increased use and evolving forms of governance instruments seeking to promote sustainability across increasingly complex and varied contexts. These primarily voluntary instruments combine guidance on sustainability strategy and/or monitoring with marketable public information, such as certifications, ratings, and reports, to incentivise take-up. Whilst they are typically based on standardised assessment criteria, recent academic literature emphasises more context-sensitive and systems-based, or 'regenerative,' approaches. We evaluate these differing approaches by adapting the concept of 'legitimacy', often applied to product certification, for this broader family of governance instruments. Prior research finds that standardised approaches have achieved success in take-up at the expense of other aspects of legitimacy, such as programme effectiveness and informational quality. Yet there remains a need for evaluation of established instruments based on a regenerative approach. We address this need through a focus on the One Planet Living framework established by Bioregional in the UK. Using practice-embedded, mixed-methods research, we identify achievements of the framework in terms of promoting effective, participatory and generally transparent programmes. Key limitations of the more bespoke approach concern take-up, resource requirements and the integration of measurement. Governance instruments for complex strategy and monitoring have, to date, struggled to combine programme effectiveness with scalability, suggesting there remains a need to develop more scalable regenerative approaches.
\end{abstract}

\section{Introduction}

There has been much academic discussion of a shift from hierarchical government to networked governance, with a loss of traditional democratic sources of control and greater involvement of private actors (Steffek, 2009). Product certification schemes have received considerable attention as an example of this trend, with analyses focusing on their non-state, voluntary and market-driven characteristics (Bernstein and Cashore, 2007), and their legitimacy and effectiveness (Bäckstrand, 2006; Mena and Palazzo, 2012). However, a wider family of related governance instruments can be identified. These are primarily voluntary (although they may be incorporated into state regulation), and provide guidance on planning for sustainability and/or monitoring progress. Such guidance is translated into any given context, resulting in documented outputs (e.g. plans, strategies, designs, targets or monitoring). These are assessed or verified, generating public information (e.g. certifications, ratings, verified targets or reports) which is marketable or reputation-enhancing, and provides an incentive for take-up. 
Public information is therefore integral to such a governance model, which has been called 'governanceby-disclosure' (Gupta, 2008), or 'information strategies' (Gunningham and Sinclair, 2017). In an effort to ensure the trustworthiness of such information, external assessment or verification processes are used. This has led to a trend towards standardised criteria to support objective and impartial processes, such as those codified into ISO conformity assessment standards. Standardisation is defined here as the use of replicable, concrete, verifiable criteria which attempt to minimise ambiguity and discretion, such as measurable targets, or verifiable actions. Conceptions of standardisation tend to refer either to the consensus process by which standards may be developed, the promotion of some degree of uniformity across contexts, or a combination of the two (Elgert and Krueger, 2012; Joss and Rydin, 2018). Here we align with the second approach.

Over the last two decades, such instruments have arisen for application across increasingly complex and varied contexts: basic units of urban space or organisation, such as neighbourhoods, large companies or cities. Across these domains, the question arises of how to formulate strategic planning and monitoring and whether standardisation is the most effective approach. Recent academic literature often takes a more context-sensitive, systems-based, or 'regenerative' approach. This emphasises the complex interconnections between and local specificity of the range of factors involved in assessing sustainability (Boyle et al., 2018; Conte, 2018; Gibbons, 2020). On this view, some standardised approaches rely on limited or over-prescriptive notions of sustainability. Instead, the need is emphasised for a more holistic and indeed ambitious view of sustainability, to be achieved through engagement, collaboration and participation. This highlights the need for empirically orientated, detailed analysis of established sustainability instruments aligned with a regenerative perspective. Addressing this need, this project assesses Bioregional's One Planet Living framework (OPL), an internationally recognised framework explicitly motivated by holistic systems thinking. We assess OPL in comparison with standardised approaches, through a focus on legitimacy and related themes such as effectiveness and scalability.

The paper is structured as follows. Section 2 introduces our conceptual focus on legitimacy, reviewing and further developing the concept in relation to the family of instruments considered here. Section 3 reviews academic evidence on standardised approaches in terms of legitimacy. Section 4 introduces our empirical focus on the One Planet Living framework, whilst sections 5 and 6 present our methodology and findings. Section 7 concludes the paper.

\section{The effectiveness and legitimacy of sustainability governance}

Standardised approaches have gained widespread usage and acceptance, yet within academic literature, their effectiveness is contested. This section explores the emerging regenerative perspective as a model 
of effective sustainability. It then introduces the concept of legitimacy, to broaden the evaluative approach beyond effectiveness and take a more comprehensive view.

\subsection{Regenerative sustainability and shifting paradigms}

Gibbons (2020) distinguishes between three sustainability paradigms: conventional, contemporary, and regenerative. Whilst the first tends to focus on technical aspects or fragmented parts of a system, the regenerative worldview aims for thriving whole living systems, emphasising the interdependence and interconnection of their different elements, centring upon the 'inner sustainability' of human beliefs and values as an important leverage point in driving sustainability. Although relatively recent, this emerging regenerative approach aligns with well-established systems thinking in sustainability assessment literature (Bell and Morse, 2008; Regeer et al., 2009). Drawing on recent literature (Boyle et al., 2018; Conte, 2018; Gibbons, 2020; Monno and Conte, 2015), we can identify systemic sustainability challenges and posit how regenerative sustainability instruments would respond to these, as shown in Table 1 below.

Table 1. Potential characteristics of regenerative sustainability instruments.

\begin{tabular}{ll}
\hline Characteristics of challenge & Response \\
\hline Complex & Flexible, context-sensitive \\
Entrenched & Ambitious, restorative \\
Cross-cutting & Broad and holistic, considering interrelationships between system parts \\
$\begin{array}{l}\text { Involving many, often } \\
\text { fragmented actors }\end{array}$ & $\begin{array}{l}\text { Fostering shared endeavour, collaboration and co-creation across groups, } \\
\text { boundaries and scales }\end{array}$ \\
Driven by values and beliefs & $\begin{array}{l}\text { Fostering communication, engagement, learning and inclusion of non- } \\
\text { experts }\end{array}$ \\
Continuously changing & Dynamic, adaptable \\
\hline
\end{tabular}

Similar conceptual shifts and critiques have arisen in regulatory theory and practice more generally. In response to the limitations of traditional, state-led 'command and control' regulation and standardised approaches, alternative, more flexible models of regulation, assessment and accountability have been developed. Responsive regulation employs more discretionary accountability processes, being sensitive to the motivations of those being held to account (Braithwaite, 2011). Meta-regulation gives greater responsibility and discretion to industry in its own regulation (Grabosky, 2017), sometimes resulting in more discretionary assessment. Although sustainability instruments have been widely studied, there is a shortage of empirical work on less standardised and more discretionary approaches. 


\subsection{The concept of legitimacy}

The question of what makes a given institution a 'legitimate' response to matters of public interest is a central issue in political science, yet remains highly contested and elusive. Steffek (2009) argues the question has become more relevant due to a shift to networked governance. In a prominent article on organisational management, Suchman (1995: 574) defines legitimacy as:

A generalized perception or assumption that the actions of an entity are desirable, proper, or appropriate within some socially constructed system of norms, values, beliefs, and definitions.

Analyses of legitimacy can take a sociological perspective, enquiring whether an institution is widely regarded as legitimate. Or they can take a normative perspective, focusing on whether institutions should be regarded as legitimate, and opening up the possibility of critiquing accepted institutions (Black, 2008). Most explorations of the legitimacy of voluntary sustainability governance have focused on a narrow subset, namely product certification schemes. These often (but not always) take a broadly normative approach, evaluating 'input' and 'output' legitimacy (Bäckstrand, 2006; Mena and Palazzo, 2012). Input legitimacy derives from being responsive to the interests of stakeholders, i.e. democratic legitimacy. Output legitimacy stems from effectiveness in producing sought outcomes, such as sustainability improvements. Much of this literature also highlights transparency as an important component of legitimacy (Bäckstrand, 2006). When applying legitimacy to certification schemes, such literature generally presumes a link between standardisation and legitimacy (McDermott, 2012), for example by assessing the participatory and transparent development of standards, and their enforcement (e.g. Mena and Palazzo, 2012). The concept has been applied in limited detail to rating tools (Holden, 2013), where analysis focuses on input legitimacy. More sociological literature, commonly focused on organisational legitimacy, analyses audience perceptions, and encompasses a broader range of concerns alongside perceived normative legitimacy. These include pragmatic sources of legitimacy deriving from user self-interest, regulatory legitimacy based on regulatory alignment, and cognitive legitimacy based on comprehensibility or 'taken-for-grantedness' (Lister, 2003; Suchman, 1995).

\subsection{Defining legitimacy functions}

Applying the concept of legitimacy to a wider family of sustainability instruments requires some adaptation. The legitimacy approach here makes a distinction between the 'programme' level and the 'systemic' level, considering both the local contexts and processes emphasised by regenerative perspectives, and the system level scalability achieved by standardised instruments. Drawing on existing literature, it incorporates aspects of both normative approaches (stakeholder input, effectiveness, and informational quality) and sociological approaches (pragmatic, regulatory and 
perceived normative legitimacy). These are incorporated into three fundamental legitimacy functions, shown in Table 2 below. Firstly, instruments can be evaluated at the programme level according to how effectively they drive sustainability practices and outcomes, via effective and democratic processes. This incorporates the more process-oriented emphasis of the regenerative perspective, and adapts the concept of input legitimacy to apply to local contexts. Second, we can appraise the outcomes of instruments at a systemic level, and the factors driving take-up processes. Finally, we can assess the quality of public information and transparency, such as information about sustainability practices and outcomes. Across these three functions, mirroring the input/output legitimacy distinction, we distinguish between process and outcome, with outcomes corresponding to output legitimacy (or information about this), and processes concerning how those outcomes are achieved. The typology does not refer to the process of instrument development, as existing literature does, but this could also be included in the table as a fourth function/process for more standardised approaches.

Table 2. Legitimacy functions of complex sustainability governance instruments.

\begin{tabular}{lll}
\hline Legitimacy function & Processes & Outcomes \\
\hline Programme level & $\begin{array}{l}\text { - Engagement and collaboration } \\
\text { - Stakeholder input }\end{array}$ & $\begin{array}{l}\text { Extent of sustainability } \\
\text { outcomes }\end{array}$ \\
\hline $\begin{array}{l}\text { Systemic level } \\
\text { - Pragmatic legitimacy } \\
\text { - Role within regulatory policy } \\
\text { - Perceived normative legitimacy } \\
\text { and transparency }\end{array}$ & - Transparency of processes, e.g. instrument \\
& development, implementation or assessment & $\begin{array}{l}\text { Level of take-up, impact } \\
\text { and/or influence }\end{array}$ \\
\hline
\end{tabular}

Programme level. We may hope that sustainability instruments drive improved 'sustainability' outcomes within the immediate networks of each user. Such instruments inevitably vary in how they define the social, economic and environmental dimensions of the contested concept. However, a common basis for evaluating effectiveness is the growing acknowledgement that significant, major, or transformative improvements are now required relative to an unsustainable business-as-usual, such as rapid decarbonisation among wealthier actors or the protection and restoration of deteriorating ecosystems (Ceballos et al., 2017; Jackson, 2019; Masson-Delmotte et al., 2018). For a regenerative approach, effective outcomes would entail a shift towards healthy, thriving human and ecological systems, through context-appropriate and holistic approaches that account for local characteristics and complexities.

Regenerative perspectives also highlight the importance of effective collaboration and engagement during programme delivery, although it is not presumed here that specific processes necessarily lead to better outcomes. Programmes may also need to include/respond to wider stakeholder interests, through participatory or representative processes. Whilst the design and development of standardised 
instruments has often incorporated stakeholder input, analyses have found standardisation reduces the scope for local input, thus de-politicising sustainability, as explained further below. A more contextsensitive approach to 'input legitimacy' would also consider the deployment phase. Where applicable, assessment and accountability processes can be evaluated according to their ability to drive positive, context-appropriate outcomes, and could include more flexible processes of the kind found in regulatory theory.

Systemic level. This concerns whether governance supports a wider transition to systemic sustainability, such as across sectors or countries. It may do so by directly shaping effective programmes (Mena and Palazzo, 2012), or indirectly, for example by influencing the wider legislative and governance context. There is a need to consider not just whether instruments achieve widespread take-up, but how they come to be adopted. Whilst the approach taken here is ultimately normative, it recognises the importance of user perceptions and concerns in achieving systemic take-up and outcomes. It therefore incorporates more sociological aspects of legitimacy, specifically from the perspective of instrument adopters. User adoption will generally involve some pragmatic considerations of self-interest. A fully self-interested approach might involve a simple calculus between the commercial benefits of certification weighed against costs (Schepers, 2010). There may also be regulatory drivers to adopt otherwise voluntary instruments (such as in timber import legality verification). Also important for real-world take-up is perceived normative legitimacy, leading to the view that instruments ought to be adopted, for example (Hurd, 1999). Deephouse and Carter (2005) distinguish between reputation, based on relative evaluations between organisations, and legitimacy, the extent to which institutions fulfil societal expectations. However, Suchman (1995) takes a broader view, identifying relative factors such as leadership as potential sources of legitimacy. Here we take the latter approach, focusing on any normative perceptions which may drive the adoption of instruments. Cognitive legitimacy could be incorporated where deemed relevant, for example where standardised approaches have gained a degree of 'taken-for-grantedness'.

Public information and transparency. Providing public information is a key function of the instruments considered here. They provide information about their users' achievements, either summary information (e.g. certifications or ratings) or detailed information (e.g. plans or reports), which can incentivise adoption. Standardised assessment criteria or processes themselves can also be made public. Public information has the potential to help foster understanding, improve decision-making, and provide accountability. Indeed, according to Mason $(2008,9)$, "transparency in governance is always relational: it is invoked to support other, more primary, social purposes and values." However, evaluating governance in these terms requires a focus on the quality of public information itself: how far it fosters critical understanding rather than simply reflecting positively on unsustainable or business-as-usual practices. 


\section{A review of standardised approaches}

This section explores dominant standardised approaches to guiding and assessing sustainability across complex urban and organisational contexts. It focuses on prior literature relevant to the three legitimacy functions and the following models of instrument, asking whether there is a need for other approaches:

- Rating tools/indices: Overall sustainability rating or index scores, based on qualitative and quantitative criteria which are aggregated using credits or points.

- Target-setting initiatives: Validated carbon reduction targets set using an approved methodology, combined with progress monitoring and reporting.

- Process standards: Process-oriented guidance often used with certification.

- Indicator guidelines: Guidance on monitoring and disclosure of sustainability performance for single or multiple topics, for verified reporting.

\subsection{Programme level: standardised models}

An important question is how guidance codifies the topic of sustainability to foster effective programmes. It may do so via aspirational goals, for example the United Nations Sustainable Development Goals (SDGs), or more verifiable sustainability actions, processes, indicators or targets. A goal-oriented approach would seem to offer the opportunity of combining ambitious aims with flexibility and context-appropriateness, and would align with typical strategy or programme management (Regeer et al., 2009; Zall Kusek and Rist, 2004). Instead, however, standardised approaches focus primarily on more easily verifiable criteria. Whilst product certification schemes often include universally required targets, instruments for large-scale, complex and varied urban and organisational contexts tend to incorporate more flexibility. To do so, instruments may vary two characteristics which are evident in the literature, prescriptiveness and coerciveness (Gunningham et al., 1998). Prescriptiveness concerns how specifically they determine the type and extent of improvement. Some approaches focus on more prescriptive targets, whilst others focus merely on indicators or processes - thereby not incorporating sustainability aims. Coerciveness, in the context of voluntary instruments, concerns whether criteria are fixed requirements for formal recognition, and whether they are enforced via strict accountability processes.

Rating tools and indices combine a range of qualitative and quantitative criteria into an overall rating or score, using a common points or credits system. This model encompasses sustainability aims/targets and technical guidance across multiple topics, and is therefore particularly comprehensive. Prescriptiveness is made possible through a less coercive approach, allowing for varying levels of performance across criteria. Yet the model has major inadequacies, explored here through a focus on urban sustainability rating tools, which have been extensively analysed. A focus on rating does not 
always imply a strong integration with strategy or improvement in practice, and tools for buildings, neighbourhoods and cities have all been found to encourage the 'chasing' of easier to obtain points (Burnett, 2007; Elgert, 2018; Garde, 2009), often having little impact. Academic research also provides specific critiques of rating tools from a systems-based or regenerative perspective (Boyle et al., 2018; Conte, 2018; Conte and Monno, 2012; Gibbons, 2020). They are viewed as overly prescriptive, marketled, expert-led, static, and too focused on specific technical areas while lacking an ambitious, holistic, context-sensitive, collaborative, engaging, long-term and dynamic approach. Building rating tools have been found to create perverse outcomes (Greenwood et al., 2017; Schweber, 2013), and neighbourhood or city tools have been critiqued for limiting local stakeholder input and de-politicising the topic of urban sustainability (Boyle et al., 2018; Elgert, 2018). One potential benefit of standardisation highlighted for city tools is that comparability helps 'cross-pollination' and learning among top performers (Elgert, 2016).

Target-setting initiatives offer the benefit of a performance-based approach linked to international climate science. The Science Based Targets initiative (SBTi) is a standardised example based on validated targets, defined methodologies and verified reporting. It allows some flexibility in targetsetting methodologies, and accountability focuses on reporting rather than sanctioning underperformance. However, whilst additional tools are sometimes used to consider co-benefits to climate action, initiatives such as the SBTi do not address a range of sustainability concerns and planetary boundaries in their basic approach (Haffar and Searcy, 2018). Hence, the single-topic approach is not a fully broad and holistic one, from a regenerative perspective. Moreover, the rigour that may be hoped of such a standardised approach is not always present in practice (Giesekam et al., 2021). The SBTi permits annual emissions reductions of $2.5 \%$, far less than what is appropriate to wealthy actors aiming for $1.5^{\circ} \mathrm{C}$ of global warming (Jackson, 2019; Masson-Delmotte et al., 2018).

Two further approaches do not codify sustainability aims such as targets. Process standards include environmental management systems such as ISO 14001, and indicator guidelines include the Global Reporting Initiative for companies, or the GHG protocol, often used with external verification. Environmental management systems have been found to have many purely 'symbolic' users for whom practices are not improved (Hertin et al., 2008; Potoski and Prakash, 2013). Corporate reporting is unlikely to have a major impact on strategy in many cases (Barkemeyer et al., 2015; Thijssens et al., 2016). Hence, focusing primarily on indicators or processes can result in business-as-usual practices.

Overall, the reliance on standardised criteria tends to limit the design of sustainability instruments, when compared with a regenerative approach. Rating tools codify a range of targets, but have been found to lack ambition and holism, and be overly prescriptive. Target-setting initiatives, or indicator- and process-based approaches, whilst potentially useful supplements to strategy, lack integration with a broad range of sustainability aims. In general, outcomes are variable and highly dependent on the 
motivations or capacity of adopters, and information-based incentives appear to be poor substitutes for intrinsic motivation.

\subsection{Systemic level}

Standardised and replicable sustainability governance has achieved moderate to widespread levels of take-up in some areas, demonstrating scalability. Corporate reporting guidance has achieved widespread coverage among large companies (KPMG, 2017). Other instruments with significant coverage include building-level rating tools, climate initiatives and environmental management systems. They are accompanied by a range of incentives for take-up, such as commercial drivers, incorporation into policy, reputational or political benefits, or convenient access to technical knowledge (Fuerst and McAllister, 2011; SCSKASC, 2012; Schweber, 2013; Elgert, 2016, 2018). One notable benefit of standardised instruments is that they can be more easily integrated into a wider private or public policy mix, for example as reporting requirements (KPMG, 2017), or public procurement requirements (Schweber, 2013), helping drive take-up. However, they can entail significant costs, often related to gathering and verifying data or certification, which can reinforce inequalities by excluding important but less wealthy actors at a systemic level. This is dynamic has been found across diverse sectors including product certification and city-scale rating tools (Brandi et al., 2015; Elgert, 2018, 2016).

Merely achieving take-up, however, does not necessarily result in widespread impact, which is dependent on local outcomes. The instruments reviewed here have often been found compatible with business-as-usual practices. For example, the highest building ratings are achieved by a very small proportion of all buildings built (Van der Heijden, 2017). Corporate reporting, whilst widespread, often does not significantly alter corporate sustainability strategy. The overall impact of recent climate initiative pledges was estimated to be small if realised (PBL et al., 2018), although this may increase as coverage increases. Nevertheless, such instruments may achieve more indirect impacts or lay the groundwork for later changes, such as driving and mainstreaming new practices beyond regulation (SCSKASC, 2012).

\subsection{Public information and transparency}

The attempt to generate trustworthy public information, such as certifications or ratings, is a driving factor behind standardisation. Yet the studies cited above cast doubt on the quality of much of this information, where it reflects positively on business-as-usual practices. Such instruments have been made accessible to a wide range of users, including the unambitious, yet to incentivise take-up such information reflects positively on them. 
Corporate sustainability reporting has received extensive attention in literature regarding informational quality. One argument for standardised, transparent, comparable public data is to prevent 'cherrypicking', i.e. the deliberate selection of indicators that reflect most positively on users. This suggests that there can be a balance to strike between flexibility and comparability where public accountability and learning are important. For example, even for 'standardised' reporting, corporate influence has led to reduced comparability and to less open and accessible ways of presenting data (Dingwerth and Eichinger, 2010; Levy et al., 2010), and optional indicators can be 'cherry-picked' to reflect positively on users (Guthrie \& Farneti 2008; Milne \& Ball 2008). New evaluation criteria are also required if corporate reports are to reflect strong concepts of sustainability (Landrum and Ohsowski, 2018; Moneva et al., 2006), again suggesting the need for integration with ambitious sustainability aims.

\section{Introduction to the One Planet Living framework}

The One Planet Living framework (OPL), developed by the U.K. charity Bioregional, takes an explicitly systems-based and holistic approach (Bioregional, 2018). Its 'hearts and minds' focus emphasises the importance of emotions, beliefs and values, echoing the regenerative approach of Gibbons (2020). OPL guidance stresses the need for leadership and 'heroism' to effect wider system change, and Bioregional selects partners for their level of commitment. Hence the tool represents a pertinent case study for assessing the challenges and opportunities involved in regenerative rather than standardised approaches to sustainability assessment.

OPL was distilled from the learning at BedZED, a landmark neighbourhood development in Surrey, UK, completed in 2002. Given this background in urban sustainability, OPL has been applied most frequently to the property sector but has sought to provide a flexible and adaptable 'common language' across many sectors and applications (see case studies below). The concept of 'One Planet Living' is based on a regenerative vision of thriving human and ecological systems, and expressed as people living happy and healthy lives within the limits of the planet, leaving space for wildlife and wilderness (Bioregional, n.d.). Rather than standardised criteria, the framework consists of ten flexible, fluid and open-ended 'principles' built around this vision, which are deliberately non-prescriptive (Bioregional, 2018). They range from health and happiness, equity and economy, and culture and community, to the sustainable use of land, water, food, transport, materials, and energy. The 'zero carbon' energy target is the least flexible part of OPL, being its only definitive (and generally most challenging) performance guideline ${ }^{1}$. Although such a goal-oriented 'common language' is uncommon among sustainability

\footnotetext{
${ }^{1}$ By comparison, in 2011, only $0.1 \%$ of buildings certified with the Code for Sustainable Homes met its zero carbon Level 6 (Lane, 2011). Maximum LEED credits are provided if only $10 \%$ of energy is provided by on-site renewables (USGBC, 2014).
} 
instruments, it is similar to the UN SDGs, which Bioregional was involved in lobbying for (Bioregional, n.d.).

OPL's formal process involves creating a context-specific 'action plan', containing outcomes, actions, indicators, and targets for each principle. During implementation, OPL users are expected to monitor and report on progress through an ongoing, and sometimes long-term and iterative relationship. Action plans and reports, moreover, are published publicly, providing transparency. Bioregional has so far worked with approximately 30 users, a low number relative to other sustainability instruments, partly reflecting the bespoke, partnership-based relationships of Bioregional. They provide flexible, discretionary forms of recognition as a mark of excellence (first 'endorsement', now 'leadership recognition'), assessing commitment as much as the content of plans (Bioregional, 2018). Bioregional partners receive 'One Planet' status, and they can now receive this even if they do not achieve leadership recognition. Such discretionary forms of public recognition have attracted criticism or suspicion from those comparing OPL with more conventional, standardised certification schemes (Cornick, 2016).

In recent years, to facilitate scaling up the use of the framework, OPL has expanded into the digital sphere, via the development of the OnePlanet platform (OnePlanet, n.d.) for developing plans, monitoring, and reporting. Due to being relatively recent, the use of the digital platform is not the focus of analysis here.

\section{Methodology}

The methodology for this study is designed to gain an in-depth understanding of how OPL addresses each of the legitimacy functions defined above. With OPL being neither standardised nor heavily documented, there was a need to unpack the practices involved in using the framework that might appear to be a 'black box'. Hence, the approach was to understand the perspectives of Bioregional staff and co-founders, as well as OPL users, through participant observation and a series of case studies. This empirical work was carried out by one of the authors over three years between 2016-2019. During this time, the researcher was embedded in Bioregional, also working on enhancements to OPL $^{2}$ and assisting with the monitoring and oversight of OPL projects. This provided an opportunity for meetings and access to programme documentation, yielding unfiltered insights which are difficult to obtain through other methods. The case study research and practice work were carried out in parallel, being distinct, while informing each other. The relationship between the researcher and Bioregional may give rise to concerns of bias. However, the case study research was kept separate from the other work for Bioregional. The latter was not the subject of the evaluation presented here. The positionality was that

\footnotetext{
2 These included OPL indicator sets (Bioregional, 2017, 2016), further guidance documentation, and the conceptual architecture of the digital platform.
} 


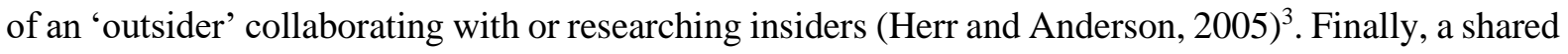
interest in promoting sustainability need not entail bias. Indeed, broadly sharing the values of an organisation can motivate critiques concerned with how to realise those values most effectively.

The engagements with Bioregional and OPL users, further detailed below, gave opportunities for extensive discussions about the merits and limitations of various approaches to codification within OPL, such as the degree of prescriptiveness or comparability between projects which would be desirable. The research does not presume the superiority of any specific practices, such as developing and enforcing 'objective', standardised assessment criteria. Rather, an interpretive or constructivist approach is adopted, which involves sensitivity to contexts, balanced regard for the views of research participants, avoiding imposing inconsistent meanings and a cyclical, dialectic research process (Guba and Lincoln, 2001; Schwandt, 1994). To enable an in-depth understanding of OPL processes, two case studies were selected and explored in depth. As explained below, these were supplemented by further 'mid-level' and 'limited depth' cases to further inform the assessment of OPL across a range of geographical and sectoral contexts.

\subsection{Enquiry and observation}

A first, exploratory research phase comprised of participant observation, including weekly visits to Bioregional's offices for the first year, as well as project site visits and engagement during the following two years. This enabled the researcher to develop their expertise on OPL to practitioner level, becoming conversant in the details of OPL and the case studies. Two OPL partnerships on which the researcher had contributed were selected and became in-depth case studies, representing the two main sectors of OPL. Sutton has been the longest-running local government partner and Northwest Bicester (NW Bicester) is a large eco-development. At a later stage, the case study research developed through more structured approaches to enquiry, primarily interviews. Two further 'mid-depth' case studies were added: SOMO Village in the US and White Gum Valley in Australia, new communities exhibiting distinctive collaboration and engagement practices.

The research included 17 semi-structured interviews with 12 participants, 7 being current or former Bioregional staff, and 5 being OPL users associated with four case studies. To gain further data insights from individuals and organisations outside Bioregional, the user interviews were complemented by direct participant observation of the two in-depth cases described above, including an especially complex, challenging and under-resourced programme (Sutton), observing meetings and events with a wide range of internal and external stakeholders. Additionally, there was extensive document analysis of 19 total case studies, illustrating sustainability performance. The interviews addressed perceived

\footnotetext{
${ }^{3}$ Research funding was provided externally, and no income was received directly from Bioregional.
} 
strengths, challenges, or limitations of the framework related to all legitimacy functions. This especially yielded insights about programme level effectiveness, stakeholder participation, and OPL take-up. In relation to these issues, it is felt that the interviews reached a good level of saturation. The researcher also held a presentation and discussion about overall research progress during an intermediary stage, where Bioregional staff provided feedback.

\subsection{Document analysis}

OPL recognition requires especially extensive programme documentation, an analysis of which gave a comprehensive, detailed understanding of case studies that supplemented insights from interviews. It also enabled the inclusion of a broader range of case studies, covering those already mentioned and some further 'limited-depth' ones, all listed below. 70 action plans and reports were analysed in total. This was especially helpful in evaluating programme effectiveness, public information and transparency.

Programme effectiveness was assessed by examining categories of practices and outcomes achieved across case studies. Given the broad range of sustainability principles within OPL, a focus was placed upon zero carbon energy for buildings and the related issue of sustainable materials. Fulfilling OPL zero carbon guidelines is both especially challenging and more easily comparable across projects. Also of interest were collaboration and engagement activities identified through document analysis (supplementing interviews), a distinctive feature of the OPL approach illustrating some of its more 'regenerative' processes. Their links to outputs and outcomes were identified where possible. The quality and regularity of reports indicate the nature of accountability and the strength of the oversight and guidance relationship, which largely relies on monitoring.

The transparency and quality of plans and reviews were evaluated through considerations such as: their existence/availability; whether they provide a clear overview across OPL principles; the regularity of reporting; whether activities and outcomes are monitored; the comparability of select indicators; and whether reporting could be improved in relation to these areas. It was not presumed that highly extensive or burdensome monitoring should be required. Regarding 'One Planet' status, the quality of such summary information links to the issue of programme level effectiveness. If the achievements of OPL projects broadly corresponded to their stated aims, this implies their overall 'One Planet' status is informative.

\subsection{Case studies}

Case studies were selected to reflect the range of contexts where OPL has been adopted. Due to the background of Bioregional in property development, OPL has been most extensively applied to the 
creation of new communities of various scales, where the framework is applied across design, construction and management/operation. OPL has also been applied to local government and city programmes, which provide insights into the challenges of fostering sustainability at large, complex scales, across fragmented actors, and often on limited budgets. In addition to the field of "urban sustainability', OPL has in some cases been applied in other sectors: a major home retailer, an engineering consultancy, two eco-tourism resorts, and a school. These last examples have established OPL as a cross-sectoral framework.

Table 3 provides an overview of case studies. These include 8 new communities (plus an apartment block within one of these), all local government/city programmes, and all projects in other sectors. Not all new communities were selected, and those included were selected according to their location cluster.

Table 3. Overview of OPL projects by location cluster or group, where applicable.

\begin{tabular}{|c|c|c|c|c|}
\hline Cluster/group & $\begin{array}{l}\text { Organisation or } \\
\text { community }\end{array}$ & Sector/type & Description & $\begin{array}{l}\text { Action } \\
\text { plan(s) }\end{array}$ \\
\hline \multirow[t]{2}{*}{$\begin{array}{l}\text { Sutton, London } \\
(U K)\end{array}$} & $\begin{array}{l}\text { BedZED (OPL } \\
\text { progenitor) }\end{array}$ & $\begin{array}{l}\text { New } \\
\text { community }\end{array}$ & Residential/mixed neighbourhood & N/A \\
\hline & $\begin{array}{l}\text { London Borough of } \\
\text { Sutton** }\end{array}$ & $\begin{array}{l}\text { Local } \\
\text { gvt./city }\end{array}$ & $\begin{array}{l}\text { Local government and district-wide } \\
\text { programme }\end{array}$ & 2009 \\
\hline \multirow[t]{2}{*}{ Brighton $(U K)$} & One Brighton & $\begin{array}{l}\text { New } \\
\text { community }\end{array}$ & Residential/mixed apartment blocks & 2006 \\
\hline & $\begin{array}{l}\text { City of Brighton and } \\
\text { Hove }\end{array}$ & $\begin{array}{l}\text { Local } \\
\text { gvt./city }\end{array}$ & $\begin{array}{l}\text { Local government and city-wide } \\
\text { programme }\end{array}$ & 2013 \\
\hline \multirow[t]{4}{*}{$\begin{array}{l}\text { Oxfordshire } \\
(U K)\end{array}$} & $\begin{array}{l}\text { Elmsbrook, NW } \\
\text { Bicester** }\end{array}$ & $\begin{array}{l}\text { New } \\
\text { community }\end{array}$ & $\begin{array}{l}\text { Residential neighbourhood on larger } \\
\text { site (eco-town) }\end{array}$ & 2013 \\
\hline & Kings Farm Close & $\begin{array}{l}\text { New } \\
\text { community }\end{array}$ & Small rural residential development & 2018 \\
\hline & Oxfordshire & $\begin{array}{l}\text { Local } \\
\text { gvt./city }\end{array}$ & $\begin{array}{l}\text { Part of One Planet Cities programme } \\
\text { (see below) }\end{array}$ & 2019 \\
\hline & Springfield Meadows & $\begin{array}{l}\text { New } \\
\text { community }\end{array}$ & Small rural residential development & 2019 \\
\hline \multirow{2}{*}{$\begin{array}{l}\text { SOMO Village, } \\
\text { California } \\
\text { (USA) }\end{array}$} & SOMO Village* & $\begin{array}{l}\text { New } \\
\text { community }\end{array}$ & $\begin{array}{l}\text { Retrofit and further development of } \\
\text { large non-residential site }\end{array}$ & $\begin{array}{l}2007 \\
2017\end{array}$ \\
\hline & Credo High School & School & High school & 2017 \\
\hline \multirow{4}{*}{$\begin{array}{l}\text { Fremantle, near } \\
\text { Perth } \\
\text { (Australia) }\end{array}$} & City of Fremantle & $\begin{array}{l}\text { Local } \\
\text { gvt./city }\end{array}$ & $\begin{array}{l}\text { Local government and city-wide } \\
\text { programme }\end{array}$ & 2015 \\
\hline & $\begin{array}{l}\text { White Gum Valley } \\
\text { (WGV)* }\end{array}$ & $\begin{array}{l}\text { New } \\
\text { community }\end{array}$ & $\begin{array}{l}\text { Residential/mixed neighbourhood, } \\
\text { sold in unbuilt plots }\end{array}$ & 2015 \\
\hline & Evermore & $\begin{array}{l}\text { New } \\
\text { community }\end{array}$ & $\begin{array}{l}\text { Apartment block at White Gum } \\
\text { Valley }\end{array}$ & 2017 \\
\hline & $\begin{array}{l}\text { East Village at } \\
\text { Knutsford }\end{array}$ & $\begin{array}{l}\text { New } \\
\text { community }\end{array}$ & $\begin{array}{l}\text { Residential development on larger } \\
\text { site }\end{array}$ & 2019 \\
\hline
\end{tabular}


Table 3 (continued).

\begin{tabular}{|c|c|c|c|c|}
\hline Cluster/group & $\begin{array}{l}\text { Organisation or } \\
\text { community }\end{array}$ & Sector/type & Description & $\begin{array}{l}\text { Action } \\
\operatorname{plan}(\mathbf{s})\end{array}$ \\
\hline $\begin{array}{l}\text { One Planet } \\
\text { Cities } \\
\text { programmes }\end{array}$ & $\begin{array}{l}\text { Various cities/areas } \\
\text { worldwide }\end{array}$ & $\begin{array}{l}\text { Local } \\
\text { gvt./city }\end{array}$ & $\begin{array}{l}\text { Digitally enabled, area-wide, multi- } \\
\text { stakeholder programmes in five } \\
\text { locations worldwide }\end{array}$ & 2018- \\
\hline \multirow[t]{5}{*}{ Other } & Middlesbrough (UK) & $\begin{array}{l}\text { Local } \\
\text { gvt./city }\end{array}$ & $\begin{array}{l}\text { Local government and city-wide } \\
\text { programme }\end{array}$ & 2011 \\
\hline & B\&Q (UK) & Company & Large home improvement chain & 2006 \\
\hline & Cundall (UK) & Company & Engineering consultancy & 2012 \\
\hline & $\begin{array}{l}\text { Singita Grumeti } \\
\text { (Tanzania) }\end{array}$ & Eco-tourism & Conservation tourism & 2012 \\
\hline & $\begin{array}{l}\text { Villages Nature } \\
\text { (France) }\end{array}$ & Eco-tourism & New eco-resort & 2013 \\
\hline
\end{tabular}

** Indicates in-depth case studies which included interviews and participant observation.

* Indicates mid-depth case studies which included interviews.

\section{Results and discussion}

OPL is built around its ten, flexible principles. Over time, it has become the view of Bioregional's cofounders, echoed by other staff, that these principles and supporting goals provide numerous overarching benefits not explicitly articulated within the framework's documentation. A synthesis of these viewpoints is presented in table 4, highlighting alignment with a regenerative approach presented in table 1 and contrasting with more prescriptive and measurement-based approaches.

Table 4. Regenerative benefits of OPL's flexible 'principles' and 'goals'.

\begin{tabular}{ll}
\hline Characteristic & Supported process \\
\hline Aspirational, open-ended & Encouraging ambition under uncertain conditions \\
Shared common language & Coordination and collaboration across fluid boundaries \\
Communicable & Communication and engagement, including non-technical audiences \\
Holistic & Joined-up strategy creation \\
Dynamic & Iterative change and adaptation \\
\hline
\end{tabular}

While OPL's distinctive, flexible approach appears to align more with a regenerative perspective, here we analyse the strengths and limitations of such an approach in practice. What are the implications of OPL's flexible and bespoke approach? Is flexibility compatible with high-quality information? What are the reasons for OPL's limited take-up, and are they related to the 'regenerative' approach adopted? 


\subsection{Programme level}

Here we firstly present findings concerning the processes related to the planning and assessment, delivery and monitoring of OPL programmes, before providing an overview of the outcomes achieved in the case studies. Underpinning OPL processes, as explained above, is the spirit in which it is intended to be used, based on a 'hearts and minds' approach. To this end, the communicability of OPL was generally considered a strength by both staff and users, being based on a simple overall vision, appealing visuals, clear principles, a background story and a portfolio of examples. Furthermore, of particular interest is the way OPL's codification of outcomes - its flexible principles and goals - facilitate the communication, engagement and coordination processes. A broad range of examples illustrate the way OPL's shared, fluid, communicable principles act as a 'common language' that fosters collaboration, engagement and the creation of shared cultures across actors, boundaries and sectors:

- At the WGV development, OPL's scalability and cross-sector flexibility enabled the creation of nested systems of users at multiple scales. OPL was used to shape the overall land development and then engage plot buyers via training and incentives, leading a number of them to contract green building companies and adopt green practices. Evermore Apartments on-site has itself become a One Planet Community, described as a 'family' by the developer. WGV itself is located within Fremantle, itself a One Planet City.

- SOMO's developer described OPL as 'embroiled' within the organisation, having changed work practices. It uses OPL in tenant engagement, and the community has become a hub for green organisations. The on-site Credo High School has become a One Planet School, again creating a nested system of users. They teach OPL in their school curriculum.

- At NW Bicester, Bioregional used OPL to facilitate ongoing partnership working with the developer, as well as the local authority with whom Bioregional share an office building.

- For the One Brighton development, over 1,300 design, development, and construction staff were inducted into One Planet Living, with OPL used as a framework for collaboration to ensure the effective implementation of plans and designs, such as the use of low-carbon materials.

- Cundall, an engineering consultancy, use OPL to train staff, who highlighted it as an especially beneficial, enjoyable aspect of their in-house 'diploma' (Cundall, 2017). This embeddedness and flexibility have enabled Cundall to routinely apply OPL in different client projects.

- B\&Q adapt OPL across the boundaries of the company's operations, supply chains, products, and customers. It has a 'One Planet Home' product range. It uses OPL in staff training, and has published a staff sustainability newspaper, the One Planet Times. 
- For the One Planet Cities programme, shared, area-wide outcomes were identified collaboratively, which were adopted into multiple action plans for different organisations.

- OPL programmes regularly engaged residents in sustainability issues (e.g. the City of Fremantle, NW Bicester), since OPL's universal aims encourage organisations to influence citizen behaviours. However, the sustainability outcomes of such engagement efforts are difficult to gauge.

These examples highlight the value of a broad and communicable common language that can foster cultures of sustainability and support collaboration and shared endeavour, often resulting in further activity and impact. They also demonstrate how variable networks of actors are in any given context, making it difficult to create standardised models for such relationships. As well as supporting collaborative programme delivery, these processes sometimes encourage input from wider stakeholders with a direct interest in the project. OPL user interviewees described local government workshops and meetings with external partners and stakeholders (Sutton), and resident engagement and consultation for new communities (NW Bicester). However, OPL places less emphasis on processes for including the views of less engaged local stakeholders. Whilst some instruments prescribe detailed consultation processes, for example, OPL leaves this to user discretion. Responsiveness to local concerns is therefore not guaranteed.

OPL action plans are broad, requiring ambitious action across all ten principles whilst leaving it open as to how they are achieved. How well does the framework deal with interconnections and interrelationships across aspects of strategies? There is some evidence of holistic approaches such as efforts to shift culture or combine wellbeing with environmental outcomes. This has included promoting actions with multiple benefits (like food growing in cities and communities) and trying to influence cultures alongside infrastructure (e.g. promoting cycling through engagement, workshops and borrow bikes at NW Bicester). However, this aspect of OPL has not always been made explicit in OPL guidance documentation: the approach enabled, but did not guarantee, holism. For complex local government programmes, although some collaborative planning and inter-departmental working did occur, such planning and delivery could sometimes become siloed, not embodying the holistic ideal of the framework. For example, participant observation revealed that OPL principles were assigned to individuals on separate teams, rather than being used in an integrated manner for issues such as spatial planning. For Bioregional to encourage a more holistic approach, they could provide more structured procedural guidance indicating this. Recognition of this need for interconnectedness and holism in programme delivery is evident in the OnePlanet digital platform, which includes mapping tools for visualising links between different elements of a plan.

The flexibility of OPL assessment, monitoring and accountability processes bears some resemblance to the meta- and responsive regulation approaches. The model embraces discretion rather than objectivity 
and shared values rather than impartiality, as is evident in how OPL has been applied across different contexts and sectors, and in Bioregional's self-description in interviews as a 'critical friend'. OPL is understood by Bioregional interviewees to strongly encourage ambition in the face of uncertainty, with accountability being concurrently trusting, flexible and forgiving. This was described as an emphasis on progress and commitment, rather than imposing rigid expectations or punishing ambition. Hence, for example, Sutton was not threatened with sanction during the final years of its programme despite decarbonisation plans not meeting the zero carbon aim. It is, however, an exception within Bioregional's portfolio.

What have been some of the challenges or limitations of a more bespoke approach? Assessment, monitoring and oversight have not always been strong or consistent. Some Bioregional staff feel a lack of benchmarks and comparable data makes performance assessment more challenging when they are either trying to assess new programmes or compare existing ones. Users with experience of OPL monitoring regarded the process as helpful, in most cases feeding back into strategy. However, although OPL expects some form of monitoring, a lack of structured guidance can make it more challenging and less likely to occur regularly, as evident from document analysis and interviews with Bioregional staff. This then makes oversight more challenging. Assessments for long-term programmes, especially local government programmes, have sometimes been over-optimistic regarding resource requirements. However, these limitations do not necessarily detract from the framework's ability to guide effective strategies in the first instance.

Turning to an overview of the results achieved through the OPL process in the case studies, documentation reveals a diverse, ambitious range of outputs and outcomes including community spaces, food-growing spaces, extensive habitats and tree-planting, low-impact and reused materials, on-site car clubs, renewable and low carbon energy sources, together with affordable housing in line with or above local benchmarks. The review of public and private documentation, supplemented by further enquiries, reveals that almost all new communities are now run primarily on renewable energy, with the exceptions noted below. This includes four communities that primarily use on-site solar energy, or plan to. A loose definition of 'zero carbon' has been important in using appropriate solutions across locations and scales. This is a lesson learned from problems with on-site renewables in BedZED, where full on-site renewables provision had implementation problems (Chance, 2009). Renewable tariff electricity has often been used to varying degrees. Providing low-carbon heat in the UK has proven challenging; it has sometimes involved biomass and two communities use natural gas as part of their delivery of low carbon objectives, although these are close to or 'net' zero carbon. Villages Nature in France, however, has a large on-site geothermal energy system, supplying a heated lagoon. Aspirational, open-ended aims have had unexpected positive outcomes, with WGV's on-site solar achievements resulting from attracting grant funding. They also encourage users to set targets with ambitious timeframes, with all long-term 
programmes having aimed for rapid decarbonisation. B\&Q, a long-running programme, has recently procured renewable electricity for all its sites.

On the other hand, three early UK local government programmes failed to take major steps to decarbonisation as stated in their action plans, or facilitate major renewables or retrofit programmes. What explains these issues? Aside from the inherent difficulty of planning, coordinating, influencing and overseeing community-wide change and retrofit at the local government level, UK local governments had had an especially challenging decade. Between 2011/12 and 2015/16, English local authorities cut spending by $27 \%$ in real terms (Hastings et al., 2015). Despite these challenges and cuts to sustainability teams, a Sutton staff member believed that around a third of the actions and outcomes listed in its reports would not have occurred without OPL.

\subsection{Systemic level}

The achievement of numerous high-profile and award-winning projects (e.g. White Gum Valley, NW Bicester and Villages Nature) suggests that OPL has attained a degree of system-level influence, illustrating the 'leadership' and system change that Bioregional promotes in its guidance. BedZED, the inspiration for OPL, is taught as part of the UK geography curriculum. The concept of One Planet Living has appeared in unexpected places, such as a One Planet festival, and a Swiss national referendum on achieving OPL by 2050 (Hawkins, 2016). As noted, Bioregional has attempted to influence policy by working with the UN on the SDGs, and they also worked with the UK government in preparing the Eco Towns PPS 1 planning policy, all drawing on OPL. The perceived normative legitimacy of OPL was generally regarded as high by both Bioregional staff and OPL users, attracting motivated users. Yet there has been limited take-up of OPL until now, affecting the direct system-level outcomes of programmes. One issue, noted by a Bioregional co-founder, is the limited capacity of a smaller organisation (Bioregional) to promote the OPL; an institutional factor not necessarily reflecting a limitation of the framework itself - leaving space for the possibility that such approaches may be more scalable in the future if greater exposure is achieved.

There are two further key barriers to take-up related to pragmatic legitimacy. Firstly, the ambition of OPL can involve resource requirements that are not always fully offset by commercial or reputational benefits, such as costlier energy, materials, community infrastructure or human resources. Successful projects have often benefited from wider enabling conditions, such as supportive policies, projectspecific subsidies or grants, improved technology, geography, and/or supportive local cultures. All of this suggests a possible limit to highly ambitious, voluntary governance without wider conditions being more conducive, or without allowing for a greater variation in performance. A second problem arises from the flexible and bespoke approach, not making use of replicable technical knowledge. Bespoke relationships require considerable resources and can be difficult to scale, according to a Bioregional co- 
founder, who hopes that the digital platform will better combine flexibility with scalability. Bioregional staff interviewed also found a less structured approach challenging, making it more difficult to progress from initial enthusiasm to full implementation and monitoring. Although procedures could be made more structured whilst resulting in bespoke plans, a lack of structure in the planning and monitoring process also seems related to the lack of replicability in guidance, since processes cannot be anchored to the application of that guidance.

\subsection{Public information and transparency}

Bioregional provides both summary information about programmes (by granting them 'One Planet' status and leadership recognition) and detailed transparency, via plans and reports. With the marks of excellence being awarded on a discretionary basis before implementation, there is a risk that their meaning becomes diluted. Based on the analysis above, such recognition has generally been indicative of ambitious programmes and significantly above-average performance, or at least improvements. However, since programmes receive their status before implementation, they have occasionally underperformed relative to expectations (e.g. early UK local government programmes). Although oversight usually occurs, under-performing organisations have occasionally retained their One Planet status rather than being sanctioned.

OPL public plans and reports provide an overview of key activities and monitoring for each of the ten principles. This provides transparency on a flexible, case-by-case basis. Both developers and local government interviewees considered this detailed information useful and accessible. All sufficiently mature projects published at least one progress review, which, together with plans, provide a good level of transparency. However, as is evident from the document analysis and interviews, there is scope for increasing the regularity, quality, efficiency and comparability of reporting, again through greater clarity in monitoring guidance. Many programmes did not set up regular reporting. Among the local government programmes, Fremantle has most clearly linked indicators to programme activities or boundaries. Based on this learning, best practice monitoring guidance and indicators could be recommended without being coercive.

\subsection{Summary}

The ethos of the OPL approach, based on translating flexible sustainability principles into contextspecific plans, has the potential to provide benefits such as collaboration and holism, reflecting a regenerative perspective. The findings highlight the effective, participatory and generally transparent delivery of ambitious projects of such a context-sensitive approach across a range of dimensions, including zero carbon. Of particular interest is how OPL enables the engagement and collaboration of actors around a communicable 'common language' within systems and networks, supporting local 
cultures and clusters of users. However, the bespoke approach of OPL has had limitations regarding resource requirements and structure, likely affecting take-up. Relatedly, there have been challenges integrating the more technical or measurable aspects of sustainability into a bespoke approach, affecting assessment, monitoring and reporting. There is potential to improve these areas whilst maintaining a flexible and non-coercive framework. A further reason for limited take-up is the high resource requirements of an ambitious approach, though this reflects OPL's relatively high ambition as a voluntary instrument rather than a weakness of the framework itself. A final issue is the limited capacity of a small organisation to promote the framework.

\section{Conclusion: towards regenerative sustainability governance}

This article considered a family of sustainability governance instruments which provide guidance on sustainability strategy/monitoring across complex and varied contexts, and link this to marketable public information. Whilst most are based on standardised criteria, discussions of a contrasting, systems-based, regenerative approach have gained prominence in recent academic literature. This emphasises the need to be holistic, flexible and sensitive to local contexts, while also collaborative, engaging, dynamic and ambitious. A review of standardised approaches finds that they have achieved moderate to high levels of take-up, and can be incorporated into a wider policy mix. However, they are lacking in terms of promoting ambitious, holistic, collaborative and participatory programmes. Moreover, by reflecting positively on business-as-usual practices, their public information risks reinforcing rather than promoting critical reflection on the current state of systemic unsustainability. Strongly measurement-based approaches can also be costly or burdensome, excluding smaller or less wealthy actors and reinforcing inequalities.

Addressing the need for empirical studies of an established instrument that seeks to translate regenerative concepts into practice, this paper has assessed Bioregional's One Planet Living framework. OPL is assessed in terms of three legitimacy functions: promoting effective and participatory projects; achieving system-level impact; and providing high-quality information. This approach broadens legitimacy from existing literature which has focused heavily on product certification schemes, often presuming a link between standardisation and legitimacy, and focusing on the development and implementation of standards.

Being broadly aligned with a regenerative perspective, OPL enables effective, participatory projects, and the engagement and collaboration of actors around a communicable 'common language'. It also provides insights into the limitations of such a model: a context-specific, bespoke approach creates challenges related to resource requirements, structure and the integration of measurement. Yet these alone do not explain modest take-up to date: other factors include the limited capacity of a small organisation to promote the framework and the difficulty of mobilising ambitious voluntary action. No 
instrument alone is a 'silver bullet': highly ambitious and regenerative practices must be supported by cultural, financial, and other resources.

Our findings invite further reflection on the legitimacy of instruments for complex sustainability governance, and how they could fully realise their potential role within the wider context of sustainable development. An approach has yet to excel in all legitimacy functions. Standardised approaches are more easily replicable, but despite their widespread usage and acceptance, they tend to be weaker on the crucial matter of supporting effective programmes. OPL supports project effectiveness but has limitations relating especially to take-up. Addressing the challenge of scaling up is thus of pivotal importance for future efforts in promoting regenerative practices as an alternative to the more conventional, standardised approach.

\section{Acknowledgements and funding}

This research was funded by the University of Westminster. The authors gratefully acknowledge Bioregional and its affiliates for their collaboration, and Professor Simon Joss for his role in coordination and supervision during the project's early stages.

\section{References}

Bäckstrand, K., 2006. Multi-Stakeholder Partnerships for Sustainable Development: rethinking legitimacy, accountability and effectiveness. Eur. Environ. 16, 290-306. https://doi.org/10.1002/eet.425

Barkemeyer, R., Preuss, L., Lee, L., 2015. On the effectiveness of private transnational governance regimes - Evaluating corporate sustainability reporting according to the Global Reporting Initiative. J. World Bus. 50, 312-325. https://doi.org/10.1016/j.jwb.2014.10.008

Bell, S., Morse, S., 2008. Sustainability Indicators: Measuring the Immeasurable?, Second Edition. Earthscan, London. https://doi.org/10.1016/S0743-0167(99)00036-4

Bernstein, S., Cashore, B., 2007. Can non-state global governance be legitimate? An analytical framework. Regul. Gov. 1, 347-371. https://doi.org/10.1111/j.1748-5991.2007.00021.x

Bioregional, 2018. Implementing One Planet Living - A Manual. London.

Bioregional, 2017. One Planet Goals and Guidance for Cities and Regions. London.

Bioregional, 2016. One Planet Goals and Guidance for Communities and Destinations. London.

Bioregional, n.d. One Planet Living - Bioregional [WWW Document]. URL 
http://www.bioregional.co.uk/oneplanetliving/ (accessed 9.22.17a).

Bioregional, n.d. Championing the Sustainable Development Goals from 2011 [WWW Document]. URL https://www.bioregional.com/projects-and-services/case-studies/championing-thesustainable-development-goals-from-2011

Black, J., 2008. Constructing and contesting legitimacy and accountability in polycentric regulatory regimes. Regul. Gov. 2, 137-164. https://doi.org/10.1111/j.1748-5991.2008.00034.x

Boyle, L., Michell, K., Viruly, F., 2018. A critique of the application of Neighborhood Sustainability Assessment Tools in urban regeneration. Sustain. 10. https://doi.org/10.3390/su10041005

Braithwaite, J., 2011. The Essence of Responsive Regulation. UBCL Rev. 44, 475.

Brandi, C., Cabani, T., Hosang, C., Schirmbeck, S., Westermann, L., Wiese, H., 2015. Sustainability Standards for Palm Oil: Challenges for Smallholder Certification Under the RSPO. J. Environ. Dev. 24, 292-314. https://doi.org/10.1177/1070496515593775

Burnett, J., 2007. City buildings - Eco-labels and shades of green! 83, 29-38. https://doi.org/10.1016/j.landurbplan.2007.09.003

Cash, D.W., Clark, W.C., Alcock, F., Dickson, N.M., Eckley, N., Guston, D.H., Jäger, J., Mitchell, R.B., 2003. Knowledge systems for sustainable development. Proc. Natl. Acad. Sci. U. S. A. 100, 8086-8091. https://doi.org/10.1073/pnas.1231332100

Ceballos, G., Ehrlich, P.R., Dirzo, R., 2017. Biological annihilation via the ongoing sixth mass extinction signaled by vertebrate population losses and declines. Proc. Natl. Acad. Sci. 114, E6089--E6096.

Chance, T., 2009. Towards sustainable residential communities; the Beddington Zero Energy Development (BedZED) and beyond. Environ. Urban. 21, 527-544. https://doi.org/10.1177/0956247809339007

Conte, E., 2018. The era of sustainability: Promises, pitfalls and prospects for sustainable buildings and the built environment. Sustain. 10. https://doi.org/10.3390/su10062092

Conte, E., Monno, V., 2012. Beyond the buildingcentric approach: A vision for an integrated evaluation of sustainable buildings. Environ. Impact Assess. Rev. 34, 31-40.

Cornick, K., 2016. Ottawa Zibi development stirs controversy over green labels, First Nations rights [WWW Document]. Natl. Obs. URL https://www.nationalobserver.com/2016/09/01/news/ottawa-zibi-development-stirs-controversy- 
over-green-labels-first-nations-rights (accessed 7.27.18).

Cundall, 2017. Cundall Diploma lessons from learners [WWW Document]. URL https://cundallconversations.com/2017/09/18/cundall-diploma-lessons-from-the-learners/

Deephouse, D.L., Carter, S.M., 2005. An examination of differences between organizational legitimacy and organizational reputation. J. Manag. Stud. 42, 329-360. https://doi.org/10.1111/j.14676486.2005.00499.x

Dingwerth, K., Eichinger, M., 2010. Tamed Transparency: How Information Disclosure under the Global Reporting Initiative Fails to Empower. Glob. Environ. Polit. 10, 74-96. https://doi.org/10.1162/GLEP_a_00015

Elgert, L., 2018. Rating the sustainable city: 'Measurementality', transparency, and unexpected outcomes at the knowledge-policy interface. Environ. Sci. Policy 79, 16-24. https://doi.org/10.1016/j.envsci.2017.10.006

Elgert, L., 2016. The double edge of cutting edge: Explaining adoption and nonadoption of the STAR rating system and insights for sustainability indicators. Ecol. Indic. 67, 556-564. https://doi.org/10.1016/j.ecolind.2016.02.051

Elgert, L., Krueger, R., 2012. Modernising sustainable development? Standardisation, evidence and experts in local indicators. Local Environ. Int. J. Justice Sustain. 17, 561-571. https://doi.org/10.1080/13549839.2012.714756

Fuerst, F., McAllister, P., 2011. Green noise or green value? Measuring the effects of environmental certification on office values. Real estate Econ. 39, 45-69. https://doi.org/https://doi.org/10.2139/ssrn.1140409

Garde, A., 2009. Sustainable by Design?: Insights From U.S. LEED-ND Pilot Projects. J. Am. Plan. Assoc. 75, 424-440. https://doi.org/10.1080/01944360903148174

Gibbons, L. V., 2020. Regenerative-The new sustainable? Sustain. 12, 1-19. https://doi.org/10.3390/su12135483

Giesekam, J., Norman, J., Garvey, A., Betts-davies, S., 2021. Science-Based Targets: On Target? Sustainability 13, 1657.

Grabosky, P., 2017. Meta-regulation, in: Drahos, P. (Ed.), Regulatory Theory: Foundations and Applications. Australian National University Press, Acton. https://doi.org/https://doi.org/10.22459/rt.02.2017.09 
Greenwood, D., Congreve, A., King, M., 2017. The future of policy and standards for low and zero carbon homes. London.

Guba, E.G., Lincoln, Y.S., 2001. Guidelines and checklist for constructivist evaluation. Eval. Checkl. Proj. EU.

Gunningham, N., Grabosky, P.N., Sinclair, D., 1998. Smart regulation: designing environmental policy. Clarendon Press Oxford.

Gunningham, N., Sinclair, D., 2017. Smart regulation, in: Drahos, P. (Ed.), Regulatory Theory: Foundations and Applications. Australian National University Press, Acton. https://doi.org/https://doi.org/10.22459/rt.02.2017.08

Gupta, A., 2008. Transparency Under Scrutiny: Information Disclosure in Global Environmental Governance. Glob. Environ. Polit. 8, 1-7. https://doi.org/10.1162/glep.2008.8.2.1

Guthrie, J., Farneti, F., 2008. GRI sustainability reporting by Australian public sector organizations. Public Money Manag. 28, 361-366. https://doi.org/10.1111/j.1467-9302.2008.00670.x

Haffar, M., Searcy, C., 2018. Target-setting for ecological resilience: Are companies setting environmental sustainability targets in line with planetary thresholds? Bus. Strateg. Environ. 27, 1079-1092. https://doi.org/10.1002/bse.2053

Hastings, A., Bailey, N., Bramley, G., Gannon, M., Watkins, D., 2015. The cost of the cuts: The impact on local government and poorer communities. Joseph Rowntree Foundation York.

Hawkins, J., 2016. Nine surprising and inspiring places using One Planet Living [WWW Document]. Bioregional. URL https://www.bioregional.com/nine-surprising-inspiring-places-one-planetliving/ (accessed 7.26.18).

Herr, K., Anderson, G.L., 2005. The action research dissertation: A guide for students and faculty. Sage publications.

Hertin, J., Berkhout, F., Wagner, M., Tyteca, D., 2008. Are EMS environmentally effective? The link between environmental management systems and environmental performance in European companies. J. Environ. Plan. Manag. 51, 259-283. https://doi.org/10.1080/09640560701865040

Holden, M., 2013. Sustainability indicator systems within urban governance: Usability analysis of sustainability indicator systems as boundary objects. Ecol. Indic. 32, 89-96. https://doi.org/10.1016/j.ecolind.2013.03.007

Hurd, I., 1999. Legitimacy and authority in international politics. Int. Organ. 53, 379-408. 
https://doi.org/https://doi.org/10.1162/002081899550913

Jackson, T., 2019. Zero Carbon Sooner-the case for an early zero carbon target for the UK. CUSP Working Paper No 18. Guildford.

Joss, S., Rydin, Y., 2018. Prospects for standardising sustainable urban development, in: Bell, S., Morse, S. (Eds.), Routledge Handbook of Sustainability Indicators. pp. 364-378. https://doi.org/10.4324/9781315561103

KPMG, 2017. The KPMG Survey of Corporate Responsibility Reporting 2017.

Landrum, N.E., Ohsowski, B., 2018. Identifying Worldviews on Corporate Sustainability: A Content Analysis of Corporate Sustainability Reports. Bus. Strateg. Environ. 27, 128-151. https://doi.org/10.1002/bse.1989

Lane, T., 2011. Only 31 homes reach code level 6 [WWW Document]. Building. URL https://www.building.co.uk/news/only-31-homes-reach-code-level-6/5023746.article (accessed 10.15.20).

Levy, D.L., Szejnwald Brown, H., de Jong, M., 2010. The Contested Politics of Corporate Governance: The Case of the Global Reporting Initiative. Bus. Soc. 49, 88-115. https://doi.org/10.1177/0007650309345420

Lister, S., 2003. NGO Legitimacy: Technical Issue or Social Construct? Crit. Anthropol. 23, 175-192. https://doi.org/10.1177/0308275X03023002004

Mason, M., 2008. Transparency for Whom? Information Disclosure and Power in Global Environmental Governance. Glob. Environ. Polit. 8, 8-13. https://doi.org/10.1162/glep.2008.8.2.8

Masson-Delmotte, V., Zhai, P., Pörtner, H.-O., Roberts, D., Skea, J., Shukla, P.R., Pirani, A., Moufouma-Okia, W., Péan, C., Pidcock, R., others, 2018. Global warming of 1.5 C. An IPCC Spec. Rep. impacts Glob. Warm. 1.

McDermott, C.L., 2012. Trust, legitimacy and power in forest certification: A case study of the FSC in British Columbia. Geoforum 43, 634-644. https://doi.org/10.1016/j.geoforum.2011.11.002

Mena, S., Palazzo, G., 2012. Input and Output Legitimacy of Multi-Stakeholder Initiatives. Bus. Ethics Q. 22, 527-556. https://doi.org/10.5840/beq201222333

Milne, M.J., Ball, A., 2008. Wither Ecology? The Triple Bottom Line, the Global Reporting Initiative, and the Institutionalization of Corporate Sustainability Reporting. Am. Account. Assoc. 44. 
Moneva, J.M., Archel, P., Correa, C., 2006. GRI and the camouflaging of corporate unsustainability. Account. Forum 30, 121-137. https://doi.org/10.1016/j.accfor.2006.02.001

Monno, V., Conte, E., 2015. Sustainability in the built environment: integrating scales of action and evaluation. Eur. J. Sustain. Dev. 4, 51-60.

OnePlanet, n.d. OnePlanet - Sustainability made easy [WWW Document]. URL https://oneplanet.com/ (accessed 10.10.20).

PBL, Yale, NewClimate Institute, 2018. Global climate action from cities, regions and businesses.

Potoski, M., Prakash, A., 2013. Do Voluntary Programs Reduce Pollution? Examining ISO 14001's Effectiveness across Countries 41, 273-295. https://doi.org/10.1111/psj.12017

Regeer, B.J., Hoes, a.-C., van Amstel-van Saane, M., Caron-Flinterman, F.F., Bunders, J.F.G., 2009. Six Guiding Principles for Evaluating Mode-2 Strategies for Sustainable Development. Am. J. Eval. 30, 515-537. https://doi.org/10.1177/1098214009344618

Schepers, D.H., 2010. Challenges to legitimacy at the forest Stewardship council. J. Bus. Ethics 92, 279-290. https://doi.org/10.1007/s10551-009-0154-5

Schwandt, T.A., 1994. Constructivist, interpretivist approaches to human inquiry, in: Denzin, N.K., Lincoln, Y.S. (Eds.), Handbook of Qualitative Research. pp. 118-137.

Schweber, L., 2013. The effect of BREEAM on clients and construction professionals. Build. Res. Inf. 41, 129-145. https://doi.org/10.1080/09613218.2013.768495

Steering Committee of the State-of-Knowledge Assessment of Standards and Certification, 2012. Toward sustainability. The roles and limitations of certification. Washington, DC.

Steffek, J., 2009. Discursive legitimation in environmental governance. For. Policy Econ. 11, 313-318. https://doi.org/10.1016/j.forpol.2009.04.003

Suchman, M.C., 1995. Managing Legitimacy: Strategic and Institutional Approaches. Acad. Manag. Rev. 20, 571-610. https://doi.org/10.5465/AMR.1995.9508080331

Thijssens, T., Bollen, L., Hassink, H., 2016. Managing sustainability reporting: many ways to publish exemplary reports. J. Clean. Prod. 136, 86-101. https://doi.org/10.1016/j.jclepro.2016.01.098

USGBC, 2014. LEED v4 for building design and construction. USGBC Inc.

Van der Heijden, J., 2017. Urban sustainability and resilience, in: Drahos, P. (Ed.), Regulatory Theory: Foundations and Applications. Australian National University Press, Acton. 
https://doi.org/https://doi.org/10.22459/rt.02.2017.41

Zall Kusek, J., Rist, R., 2004. Ten steps to a results-based monitoring and evaluation system: a handbook for development practitioners. The World Bank. 